\title{
O IMPACTO DAS DIRETRIZES NACIONAIS PARA A FORMAÇÃO HUMANÍSTICA DO CURSO DE GRADUAÇÃO EM ADMINISTRAÇÃO PÚBLICA DA UFRRJ
}

http://dx.doi.org/10.5902/2318133842328

\author{
Vinicius Ferreira Baptista ${ }^{1}$
}

\begin{abstract}
Resumo
Neste texto discute-se os resultados da reformulação do projeto pedagógico do curso de graduação em Administração Pública de 2017 da Universidade Federal Rural do Rio de Janeiro, em cotejo com o projeto pedagógico de 2010 e as críticas contidas acerca deste em Baptista (2017). Analisamos 38 disciplinas que compõem a formação do discentes em créditos contidas no PPCGAP, especificamente nos atentando sobre ementas de 24 disciplinas obrigatórias quanto: objetivo geral, objetivos específicos, ementa, conteúdo programático, referências bibliográficas. No caso do novo PPCGAP/2017 da UFRRJ podemos situar uma formação humanística. No ciclo de formação básica, que vai do $1^{\circ}$ ao $4^{\circ}$ período, quase $65 \%$ das disciplinas abordam questões de desigualdade social, classe, gênero, raça e sexualidade. No novo PPCGAP/2017 há menção clara e direta aos tipos de desigualdades, violação de direitos e o compromisso do gestor público para com a resolução destes e outros problemas. Por fim, pode-se afirmar que o novo PPCGAP/2017 é pautado em sentido humanístico, crítico e situado em perspectiva democrática no âmbito de combate às desigualdades sociais.

Palavras-chave: projeto pedagógico, administração pública, formação humanística, UFRRJ.
\end{abstract}

\section{THE IMPACT OF NATIONAL GUIDELINES FOR THE HUMANISTIC FORMATION OF THE UNDERGRADUATE COURSE IN PUBLIC ADMINISTRATION OF UFRRJ}

\begin{abstract}
This text aims to discuss the results of the reformulation of the pedagogical project of the 2017 Undergraduate Course in Public Administration at the Federal Rural University of Rio de Janeiro in comparison with the 2010 pedagogical project and the criticisms contained about it in Baptista (2017). Methodologically, we analysed 38 subjects that make up students' training in credits contained in the PPCGAP, specifically, paying attention to the menus of 24 mandatory subjects regarding: general objective, specific objectives, menu, program content, bibliographical references. In the case of the new PPCGAP/2017 from UFRRJ, we can, in fact, situate a humanistic formation. In the basic training cycle, which runs from the first to the fourth period, almost $65 \%$ of the subjects address issues of social inequality, class, gender, race and sexuality. In the new PPCGAP / 2017 there is a clear and direct mention of the types of inequalities, violation of rights and the public manager's commitment to solving these and other problems. Finally, what we can see is that the new PPCGAP/2017 is guided in a humanistic, critical sense and situated in a democratic perspective in the context of combating social inequalities.

Key-words: pedagogical project, public administration, humanistic formation, UFRRJ.
\end{abstract}

\footnotetext{
1 Universidade Federal Rural do Rio de Janeiro, Brasil. E-mail: viniciusferbap2007@hotmail.com.

\begin{tabular}{|l|l|l|l|l|l|l|} 
Regae: Rev. Gest. Aval. Educ. & Santa Maria & v. 9 & n. 18 & Pub. contínua 2020 & p. 1-20
\end{tabular}
}




\section{Introdução}

- ste texto tem como tema a problematização de projetos pedagógicos de cursos de graduação em nível superior no âmbito da administração pública e que se relacionam com a perspectiva humanística de formação de profissionais imbuídos com o sentido público de interesse social. O foco, especificamente, em termos de desigualdades, recai acerca de gênero, diversidade sexual e raça. Não é nosso objetivo conceituar estas dimensões, tendo em vista a pluralidade de concepções, contud, a ideia é construir a percepção empregada nos documentos normativos incitados e analisados.

O objetivo é discutir as reformulações e rever pontos situados em Baptista (2017) acerca do projeto pedagógico do curso de graduação em Administração Pública (PPCGAP/2010) da Universidade Federal Rural do Rio de Janeiro no ano de 2010. Naquele trabalho nos apoiamos em documentos oficiais da referida instituição, a exemplo do plano de desenvolvimento institucional, o projeto pedagógico do curso, assim como as diretrizes curriculares nacionais no âmbito dos cursos de graduação em Administração Pública contidas em portaria do Conselho Nacional de Educação.

Neste texto trabalhamos o projeto pedagógico do curso de graduação em Administração Pública do ano de 2017 (PPGCAP/2017), reformulado institucionalmente, tendo em vista, tanto a perspectiva do tempo, assim como a necessidade de atualização conforme as DCN publicadas em 2014 e que substituiu o projeto pedagógico de 2010. Os pontos discutidos neste artigo têm por objetivo demonstrar os principais resultados do desenvolvimento da reformulação da matriz curricular do referido curso de graduação, em cotejo com as críticas desenvolvidas anteriormente em Baptista (2017).

Entendemos que o novo PPC procura desenvolver formação humanística do curso de graduação em Administração Pública da UFRRJ, diferente do projeto pedagógico anterior visto na discussão em Baptista (2017). Com a reformulação do perfil de egresso, missão, visão e estrutura pedagógica existe um potencial de incorporação das dimensões de desigualdades sociais que permita o desenvolvimento de uma análise crítica da realidade social, na tentativa de afastamento de mecanicidade e engessamento de projetos pedagógicos na área pública.

\section{Diretrizes curriculares nacionais do curso de graduação em Administração Pública}

Em 2014 o Ministério da Educação, via Conselho Nacional de Educação, publicou a resolução n. 1, de 13 de janeiro de 2014, que institui as diretrizes curriculares nacionais do curso de graduação em Administração Pública, bacharelado, e dá outras providências.

Todavia, neste texto, devemos também considerar que o primeiro projeto pedagógico do curso de graduação em Administração Pública da Universidade Federal Rural do Rio de Janeiro foi aprovado em maio de 2010, com a primeira turma no segundo semestre daquele ano, ou seja, o PPCGAP é anterior às DCN da área. Isso contextualiza que o curso não apresenta as bases exigidas pelo CNE, em termos de homogeneização de formação comum em Administração Pública. Portanto, é evidente que as críticas contidas em Baptista (2017) levam este contexto em consideração. 
O parágrafo I do art. $2^{\circ}$ das $D C N$ remete à "responsabilidade pela res publica e à defesa do efetivo caráter público e democrático do Estado" na formação do administrador público, no qual se evocam a "política, gestão pública e gestão social" como evocam temas que demandem multi e interdisciplinaridade no que se refere à pluralidade $\mathrm{e}$ diversidade de questões que envolvem a vida social (CNE, 2014).

O sentido democrático de uma Administração Pública é situado pelo "o ethos republicano e democrático como norteador de uma formação que ultrapasse a ética profissional" (CNE, 2014, parágrafo I, art. $2^{\circ}$ ), o que aponta caráter pluralista acerca de concepções diversas e modos de ser e viver condizentes com a multifacetada perspectiva que envolve viver em sociedade. Cabe à administração pública se guiar para manter este elemento democrático.

A perspectiva de sujeitos de justiça corrobora a noção básica da Administração Pública como campo importante ao desenvolvimento social, justo, equitativo e pautado em dimensões plurais políticos, religiosos e, indiscriminadamente, de agregar pessoas em convivência. Carvalho (2013) pondera que a perspectiva de cidadania não se remete ao sentido de diversas cidadanias as quais derivariam em graus ou camadas: ela é única, uma concepção plena e que não diferencie as pessoas em termos de quem as compreende ou não.

Cidadania não permite desigualdade. Não permite a ideia de pessoas iguais, porém separadas, (Davis, 2016), ou cidadania de segunda classe (Houltson, 2013) ou rebaixada (Borillo, 2015). Não existem direitos incompletos ou renegados. Benhabib (2011) considera que os sujeitos devem ser considerados plenos e jamais nivelados em concepções morais, éticas ou políticas. Fraser (2009) entende que as pessoas são sujeitos morais, assim, conceber diferentes cidadanias seria conceber diferentes pessoas morais, niveladas ao ponto em que uns sujeitos valem mais que os outros. Quando isso alcança o Estado, Young (2011) entende que se estrutura um processo de desigualdade como modus operandi do aparato estatal, ao passo em que Rawls (2001) situaria como um modus vivendi que, incorporado pelas pessoas, situa uma estrutura social.

A coisa pública é indeterminada, mas isso não significa que, como tal, padeça de uma síndrome de indeterminação (Honneth, 2000), ou seja, que quando difícil de determinar o contexto em que se desenvolve e alcance mentes e corpos, implique tal estado que permita diversas concepções distantes de um entendimento mínimo. As DCN de 2014, portanto, situam um lugar comum à Administração Pública, compreendendo-a como fundamental ao desenvolvimento das pessoas, grupos, sociedades e nações. Uma concepção que requer capacidade técnica, crítica, cultural, pessoal e filosófica dos seus atuantes.

Como toda construção social a Administração Pública é fruto de seu tempo, seja em realidade internacional, seja na brasileira. Logo, em ordem cronológica deste trabalho, o primeiro PPCGAC em 2010 é diferente do segundo PPCGAC em 2017, por considerar que em 2014 tivemos a publicação de DCN que orientam justamente os projetos curriculares. Assim, vemos uma concepção de Administração Pública se apresentar a balizar cursos de graduação.

Devemos considerar que o conteúdo exigido em DCN poderia apontar conteúdos atrelados à uma formação mais plural, aberta, cosmopolita, situada na defesa de ampliação de direitos e aplicada em permitir desenvolvimento de projetos que alcancem a 
melhoria das condições de vida das pessoas. Por outro lado também poderíamos ter concepções de conteúdos em DCN situados em lógicas deterministas de crescimento econômico, direitos mínimos, atuação mínima do Estado e direcionada em pontos que não desestruturem lógicas de mercado. Paralelamente poderíamos também admitir conteúdos em DCN cujas bases apontariam mecanismos de regulação de comportamento, estruturas morais e éticas de atuação pública e privada e noções pautadas em tradições.

Não obstante, estas divergentes concepções de Administração Pública situam diferentes formas de intervenção estatal. Ações diretivas do Estado que, conforme a base conceitual as oriente, aponta políticas públicas e instrumentos normativos relacionados com os objetivos de sua proposta conceitual. Logo, uma concepção democrática terá num curso de graduação em Administração Pública, disciplinas e ementas plurais e situadas em perspectivas de amplitude referencial, bibliográfica e metodológica. Contudo, um projeto curricular não é apenas um documento normativo.

Não desconsideremos que o parágrafo $\mathrm{VI}$ do art. $4^{\circ}$ das $\mathrm{DCN}$ aponta que é exigido do egresso "expressar-se de modo crítico e criativo diante dos diferentes contextos organizacionais e socioculturais, desenvolvendo expressão e comunicação adequadas aos processos de negociação e às comunicações interinstitucionais", assim como "ter iniciativa, criatividade, determinação e abertura ao aprendizado permanente e às mudanças", parágrafo VII no mesmo artigo (CNE, 2014). Ou seja, estamos lidando com pessoas que incorporarão e desenvolverão aquilo o que se é preconizado em documentos que orientam uma formação.

Já no art. 5ํㅜ precreve-se que

o curso de graduação em Administração Pública deverá contemplar, em seus projetos pedagógicos e na sua organização curricular, conteúdos que revelem, em uma perspectiva histórica e contextualizada, compromisso com os valores públicos e o desenvolvimento nacional, assim como com a redução das desigualdades e o reconhecimento dos desafios derivados da diversidade regional e cultural (CNE, 2014, art. 5ํ)

Desigualdades social não se refere unicamente a questão da pobreza e miséria, mas também ações discriminatórias e restritivas frente a determinados grupos sociais que acabam por desigualar a sociedade. Neste ponto mantemos a mesma lógica conceitual em Baptista (2017) para compararmos projetos pedagógicos no campo da Administração Pública.

\section{Construindo concepções ampliadas de sujeitos: o caso do PPCGAP/2017}

A formação do administrador público no Brasil é orientada pela resolução n. 1, de 13 de janeiro de 2014, do Conselho Nacional de Educação, que estabelece as diretrizes curriculares nacionais.

A Administração Pública costuma se associar com duas interpretações: uma relativamente técnica outra essencialmente políticas. Matias-Pereira (2010) situa o primeiro exemplo, pontuando-a como "gestão de bens e interesses qualificados da comunidade no âmbito dos três níveis de governo" (p. 62), tendo como base estruturas morais e do Direito. Já Bobbio (1987) aponta a segunda lógica como incumbências 
consideradas de interesse público. Notadamente entendemos a Administração Pública como um campo de ideias, conceitos e práticas que incidem sobre modos de conceituar, contextualizar, estruturar e desenvolver ações diretivas do Estado para com a sociedade.

Neste contexto, por volta dos anos 2000, o movimento de mobilização acadêmicocientífica denominado campo de públicas vem procurando desempenhar esforço de consolidar a autonomia dos cursos de bacharelado em Administração Pública em relação à área de Administração de empresas congregando diferentes cursos que se voltam ao interesse público como princípio epistemológico, ao passo de evidenciar os princípios republicanos e democráticos. Para Pires et al. (2014)

campo de públicas é uma expressão utilizada por professores, pesquisadores, estudantes, egresso-profissionais e dirigentes de cursos de Administração Pública e Políticas Públicas, Gestão Pública, Gestão Social e Gestão de Políticas Públicas, de universidades brasileiras, para designar, essencialmente, um campo multidisciplinar de ensino, pesquisa e fazeres tecnopolíticos, no âmbito das Ciências Sociais Aplicadas e das Ciências Humanas, que se volta para assuntos, temas, problemas e questões de interesse público, de bem-estar coletivo e de políticas públicas inclusivas, em uma renovada perspectiva republicana ao encarar as ações governamentais, dos movimentos da sociedade civil organizada e das interações entre governo e sociedade, na busca do desenvolvimento socioeconômico sustentável, em contexto de aprofundamento da democracia. ( $p$ 112)

Com a constituição do campo de públicas, em agregação às políticas públicas de reestruturação e ampliação das universidades públicas - Reuni -, na primeira década dos anos 2000, novos cursos ligados à área de Administração Pública, Políticas Públicas e Gestão Social foram criados em instituições de todas as regiões do país: Udesc (2004), USP (2005), Unicamp, UFMG, UnB, Ufrgs, UFRN e UFRRJ (2009), UFABC, UFLA, UFPB e UFRJ (2010). Em pouco mais de dez anos foram criados mais de 200 cursos ligados à área no país, o que inclui cursos de graduação presenciais e à distância, bem como os cursos de formação de tecnólogos (Pires et al., 2014).

Já o curso de graduação em Administração Pública "deverá propiciar formação humanista e crítica de profissionais e pesquisadores" (CNE, art. $\left.3^{\circ}\right)$. $\mathrm{O}$ art. $2^{\circ}$ compreende como princípios fundamentais: o ethos republicano e democrático; a flexibilidade como parâmetro das instituições de educação superior; a interdisciplinaridade e a transdisciplinaridade.

A revisão do $\mathrm{PPC}^{2}$ de graduação Administração Pública da Universidade Federal Rural do Rio de Janeiro foi desenvolvida por uma comissão formada em outubro de 2011 pelo colegiado do curso de graduação em Administração Pública. Tal revisão tinha como objetivo adequar o currículo do curso às mudanças observadas no contexto socioeconômico do país, ao aprendizado e às conquistas estabelecidas no campo de públicas, ao perfil dos discentes ingressos no curso nos seus primeiros anos de história, as necessidades de mercado profissional, bem como às próprias características da UFRRJ.

${ }^{2}$ Ver em: http://cursos.ufrrj.br/grad/admpublica/ppp-projeto-politico-pedagogico

\begin{tabular}{|l|l|l|l|l|r|} 
Regae: Rev. Gest. Aval. Educ. & Santa Maria & v. 9 & n. 18 & Pub. contínua 2020 & p. 1-20
\end{tabular} 
A partir do relatório elaborado pela Comissão, ao longo dos anos de 2014, 2015 e início de 2016, houve processo de debate, seguindo as orientações estratégicas do Plano de Desenvolvimento Institucional da UFRRJ (PDI, 2013-2017) e da resolução CNE/CES n. 1 , de 13 de janeiro de 2014, que institui as diretrizes curriculares nacionais dos cursos de graduação em Administração Pública. Também foram observadas as diretrizes curriculares nacionais para educação das relações étnico-raciais e para o ensino de história e cultura afro-brasileira e indígena, bem como a instituição da disciplina de Libras entre as optativas dos cursos de educação superior.

Diferentemente do PPCGAP/2010, o PPCGAP/2017 apresenta como princípios norteadores a formação ética e a função social do profissional; flexibilidade curricular; a interdisciplinaridade e a transdisciplinaridade; respeito às diferenças, diversidade e pluralidade de pensamento. Todo projeto curricular é também um projeto político: considerar a administração pública como apolítica é atrelar seu sentido à administração de empresas, mecânica e situada em lucros, uma conotação totalmente distante de seu propósito público, voltado ao cidadão e não à clientes. Portanto, este quarto princípio já demonstra mudança substancial às críticas feitas por nós anteriormente em Baptista (2017).

A formação humanística envolve a "busca, por intermédio de disciplinas do currículo e pelas diversas atividades extracurriculares oferecidas, de sensibilizar os alunos para questões sociais, políticas, culturais e éticas relativas ao País e às profissões de uma forma geral" (Baptista, 2017, p. 106). O novo PPCGAP/2017 mantém referência a princípios de base conceitual de cidadania, ética, ethos democrático, democracia, desenvolvimento social os quais o referido projeto pedagógico faz menção recorrentemente.

Ainda no PPCGAP/2010 a missão do curso compreende formar um profissional competente tecnicamente, contudo, também capaz de ser "agente transformador da realidade em que se insere" (p. 27). Há uma diferença nítida para com a missão do PPCGAP/2017 na qual o texto é "formar e capacitar profissionais qualificados para exercerem a função de gestor do Campo de Públicas, com elevado nível de consciência crítica, competência técnica e engajamento ético, buscando a construção de uma sociedade justa e democrática" (UFRRJ, 2017, p. 14). A mudança não é apenas pela qualidade do texto em relação ao sentido de público empregado, mas por tentar demonstrar que o exercício da Administração Pública é voltado à sociedade e envolve grau de complexidade em aliar saber técnico à capacidade agregadora do ser e agente público.

Já no objetivo geral do PPCGAP/2010 a base compreende formar um "profissional empreendedor e gerenciador de soluções para os problemas das organizações públicas" (2010, p. 27). No caso do PPGCAP2017 é

propiciar ao discente o desenvolvimento de competências compostas por conhecimentos, habilidades e atitudes que consolidem a capacidade crítica e reflexiva para a formação de um profissional empreendedor e gerenciador de soluções para os problemas das organizações públicas, organizações do terceiro setor e até mesmo das organizações privadas 
com e sem fins lucrativos que desenvolvam ações voltadas para o interesse público, com condições de compreender a complexidade e as contradições que delineiam a dinâmica organizacional da sociedade (UFRRJ, 2017, p. 15)

A diferença do PPCGAP/2017 está no âmbito do desenvolvimento de ações voltadas para o interesse público, tendo em vista as complexidades e as contradições: este conceito e prática, a práxis, delineia um tipo de administração pública, com afeto ao público, ou seja, situar tanto interesse público quanto desenvolvimento. Vemos aqui um objetivo mais amplo, distante das negatividades situadas.

Em Baptista (2017) tínhamos criticado que, recorrentemente, o PPCGAP mencionava cidadania sem apontar a perspectiva que a orienta. Isso foi corrigido, a priori, com o desenvolvimento do quarto princípio norteador do novo PPCGAP/2017, com o respeito às diferenças, diversidade e pluralidade de pensamento, em que "diversidades teóricas e metodológicas, assim como estimular a tolerância, o entendimento e o debate sobre as diferenças sociais, gênero, raça e sexuais que implicam na formulação de políticas públicas e intervenções do Estado na sociedade" (UFRRJ, 2017, p. 13).

Também tínhamos destacado em Baptista (2017) que o PPCGAP/2010 não apontava quais mazelas, problemas, por exemplo, situavam sua crítica aos problemas sociais. Contudo, há, no novo PPCGAP/2017, uma crítica envolvendo a noção de que o curso de graduação em administração pública da UFRRJ deveria considerar os "problemas relacionados ao transporte, emprego, educação, moradia, meio ambiente e segurança pública, além de não possuir espaços consolidados de desenvolvimento tecnológico substanciados que agreguem valor à comunidade local” (UFRRJ, 2017, p. 10).

Outra crítica que observamos em Baptista (2017) que o PPCGAP/2010 destacava que a perspectiva integrada teria entendimento engessado de curso de graduação formador de profissionais apenas e, em um segundo momento, profissionais para atuar em perspectiva de organizações públicas. Já no PPCGAP/2017 vemos um perfil de egresso que busca o "incremento da cidadania e do desenvolvimento local e sustentável" e se caracteriza "pela visão ampla das necessidades da sociedade, que contribua para a melhoria da qualidade de vida dos indivíduos e cidadão; pela promoção do interesse público e pela expansão da participação da sociedade civil na gestão do Estado" (UFRRJ, 2017, p. 17).

Outro objetivo que envolve o perfil do egresso no novo PPCGAP/2017 é que o mesmo "deverá possuir um olhar crítico e analítico dos acontecimentos que circundam as organizações, as políticas públicas e a sociedade, com vistas a garantir à responsabilidade pela res publica e à defesa do efetivo caráter público e democrático do Estado" (UFRRJ, 2017, p. 17). O que podemos observar, consequentemente, é a movimentação no entendimento de questões basilares à construção de um projeto pedagógico à formação humanística de graduados em administração pública: de uma compreensão mecânica no PPCGAP/2010 para uma outra, via PPCGAP/2017, mais orgânica, aberta e crítica acerca da conjuntura social brasileira e da capacidade do potencial da administração pública às soluções dos problemas sociais de nossa sociedade.

As mudanças podem ser observadas no quadro a seguir. 
Quadro 1 -

Matriz referente aos PPCs.

\begin{tabular}{|c|c|}
\hline PPGCAP/2010 & PPGCAP/2017 \\
\hline Princípios & Princípios \\
\hline $\begin{array}{l}\text { I. A formação ética e a função social do } \\
\text { profissional; } \\
\text { II. Flexibilidade curricular; } \\
\text { III. A interdisciplinaridade e a } \\
\text { transdisciplinaridade; }\end{array}$ & $\begin{array}{l}\text { I. A formação ética e a função social do } \\
\text { profissional; } \\
\text { II. Flexibilidade curricular; } \\
\text { III. A interdisciplinaridade e a } \\
\text { transdisciplinaridade; } \\
\text { IV. Respeito às diferenças, diversidade e } \\
\text { pluralidade de pensamento }\end{array}$ \\
\hline Objetivo & Objetivo \\
\hline $\begin{array}{l}\text { Profissional empreendedor e gerenciador de } \\
\text { soluções para os problemas das } \\
\text { organizações públicas }\end{array}$ & $\begin{array}{l}\text { Capacidade crítica e reflexiva para a formação } \\
\text { de um profissional empreendedor e gerenciador } \\
\text { de soluções que desenvolvam ações voltadas } \\
\text { para o interesse público }\end{array}$ \\
\hline Missão & Missão \\
\hline $\begin{array}{l}\text { Formar um profissional competente } \\
\text { tecnicamente, contudo, também capaz de ser } \\
\text { agente transformador da realidade em que se } \\
\text { insere }\end{array}$ & $\begin{array}{l}\text { Formar e capacitar profissionais qualificados } \\
\text { para exercerem a função de gestor do campo } \\
\text { de públicas, com elevado nível de consciência } \\
\text { crítica, competência técnica e engajamento } \\
\text { ético, buscando a construção de uma } \\
\text { sociedade justa e democrática }\end{array}$ \\
\hline Egresso & Egresso \\
\hline $\begin{array}{l}\text { Profissionais empreendedores e } \\
\text { gerenciadores }\end{array}$ & $\begin{array}{l}\text { Olhar crítico e analítico dos acontecimentos que } \\
\text { circundam as organizações, as políticas } \\
\text { públicas e a sociedade }\end{array}$ \\
\hline
\end{tabular}

Fonte: UFRRJ, 2010; 2017

O Estado é parte da construção da cidadania e dos contextos sociais que a circundam (Marshall, 1967), logo, pensar a administração pública, é pensar em quem é atingido, de que forma, em quais condições, e o que é ofertado mediante estrutura de ação diretiva do Estado. Uma compreensão mecânica de administração pública importa dimensão engessada de cidadania, fechada às noções de clientela e cidadão-cliente, como se cidadania fosse produto a ser adquirido mercadologicamente em um grande balcão, o que seria diferenciado a cada cidadão pelo seu potencial de compra. A cidadania é processo ampliado e restrito: ampliado a todos os cidadãos membros de uma comunidade política e restrita em termos de sua impossível negociação (Carvalho, 2013). Assim, o PPGCAP/2017 tenta deixar claro, ainda que em alguns momentos generalize ou seja restrito em interpretações, objetiva compreensão clara e direta do potencial da administração pública com foco no interesse social e desenvolvimento pleno da sociedade. 
A matriz curricular do curso de graduação em Administração Pública da UFRRJ em 2017 no contraponto com o projeto de 2010

No item anterior realizamos uma análise do aspecto conceitual e analítico que traz PPCGAP/2017 da UFRRJ em contraponto com os apresentados no PPCGAP/2010 discutidos em Baptista (20117).

O currículo apresentado no PPCGAP/2017 está em consonância com as diretrizes curriculares do curso de Administração Pública de 2014 e com o PDI (2013-2017) da UFRRJ, cuja organização de conteúdos revelam, numa perspectiva histórica e contextualizada, em observância aos valores públicos e o desenvolvimento nacional, considerando a redução das desigualdades e o reconhecimento dos desafios derivados da diversidade regional e cultural.

O currículo do curso de Administração Pública, com carga horária total de 3.060 horas, sendo 2.280 horas em disciplinas obrigatórias, 180 horas em disciplinas optativas, 270 horas em atividades complementares e 330 horas de estágio curricular supervisionado obrigatório. Esta carga horária total encontra-se distribuída em oito semestres;

Quadro 2 -

Quadro sintético do PPCAGP/2017.

\begin{tabular}{|c|c|c|}
\hline Grupo & Áreas & Disciplinas \\
\hline Grupo I & $\begin{array}{l}\text { Administração, de Ciências } \\
\text { Contábeis, de Ciência Política, } \\
\text { de Economia, de Direito e de } \\
\text { Sociologia }\end{array}$ & $\begin{array}{l}\text { Fundamentos do Pensamento Administrativo } \\
\text { Teorias Organizacionais } \\
\text { Contabilidade Geral I } \\
\text { Contabilidade Nacional } \\
\text { Fundamentos da Ciência Política no Campo de } \\
\text { Públicas } \\
\text { Sistema Político, Dinâmicas Econômicas e } \\
\text { Instituições no Brasil } \\
\text { Fundamentos da Microeconomia } \\
\text { Fundamentos da Macroeconomia } \\
\text { Direito Constitucional I } \\
\text { Direito Administrativo e Legislativo } \\
\text { Estudos Antropológicos e Sociológicos na } \\
\text { Administração Pública }\end{array}$ \\
\hline$\underset{\text { II }}{\text { Grupo }}$ & $\begin{array}{l}\text { Estudos antropológicos, } \\
\text { filosóficos, psicológicos, ético- } \\
\text { profissionais, bem como os } \\
\text { relacionados às tecnologias da } \\
\text { comunicação e da informação }\end{array}$ & $\begin{array}{l}\text { Filosofia e ética nas organizações } \\
\text { Comportamento Organizacional e Dinâmica } \\
\text { Humana na Administração Pública } \\
\text { Estudos Antropológicos e Sociológicos na } \\
\text { Administração Pública } \\
\text { Tecnologia da Informação I } \\
\text { Conceitos Fundamentos e Aplicação } \\
\text { Tecnologia da Informação II }\end{array}$ \\
\hline Grupo & $\begin{array}{l}\text { Leitura, escrita, expressão e } \\
\text { comunicação }\end{array}$ & $\begin{array}{l}\text { Metodologia de Pesquisa na Administração Pública } \\
\text { Disciplinas optativas }\end{array}$ \\
\hline Grupo & $\begin{array}{l}\text { Realidade histórica e } \\
\text { contemporânea da sociedade } \\
\text { e do Estado brasileiros }\end{array}$ & $\begin{array}{l}\text { Introdução à Administração Pública } \\
\text { Sistema Político, Dinâmicas Econômicas e } \\
\text { Instituições no Brasil } \\
\text { Políticas Públicas e Sociedade }\end{array}$ \\
\hline
\end{tabular}

Fonte: UFRRJ, 2017. 
Além dos conteúdos de formação básica as DCNs do curso de Administração Pública também estabelecem conteúdos de formação profissional. Tais conteúdos incluem aqueles sobre governos e políticas públicas comparadas, conteúdos metodológicos, abrangendo estudos quantitativos e qualitativos, e conteúdos complementares ou especializados. Neste ponto, no que tange os conteúdos de formação profissional voltados para estudos quantitativos, ressalta-se as disciplinas: Matemática I e Estatística Básica. Já os conteúdos complementares ou especializados podem ser percebidos nas disciplinas: Cadeia de Suprimentos na Administração Pública; Gestão Estratégica de Pessoas na Administração Pública; Sustentabilidade na Administração Pública; Negociação, Comunicação e Arbitragem; Administração Municipal; Planejamento Estratégico na Administração Pública e Planejamento e Desenvolvimento Econômico Regional (UFRRJ, 2017).

O curso de graduação em Administração Pública da UFRRJ está estruturado em dois eixos de formação profissional ou especialização. O primeiro eixo volta-se para área de elaboração e gestão de políticas públicas, enquanto o segundo dedica-se a área de gestão orçamentária e finanças públicas. Entre as disciplinas que integram o primeiro eixo pode-se destacar: Políticas Públicas e Sociedade, Elaboração de Políticas Públicas; Qualidade e Produtividade no Serviço Público; Avaliação de Políticas Públicas; Gestão e Elaboração de Projetos Públicos e Governança na Administração Pública. Entre as disciplinas que integram o segundo eixo, por sua vez, enumera-se: Gestão de Compras e Licitação; Gestão de Contratos, Convênios e Consórcios Públicos; Orçamento Público e Finanças Públicas. Nesses eixos estão englobadas disciplinas que proporcionam ao discente uma formação técnica, fortalecendo-o com relação às particularidades técnicas do Campo de Públicas.

Dentro de cada eixo de formação profissional vale destacar o papel desempenhado pelas disciplinas integradoras, que visam à consolidação da base de conhecimentos profissionalizantes: Elaboração e Gestão de Projetos Públicos; Elaboração de Políticas Públicas; Gestão de Contratos, Convênios e Consórcios Públicos e Avaliação de Políticas Públicas. Valendo acrescentar que as disciplinas integradoras também permitem colocar em prática o princípio da interdisciplinaridade e transdisciplinaridade

Do total das 38 disciplinas que compõem a formação do discentes em créditos contidas no PPCGAP, observamos que 22 se situam no eixo de disciplinas voltadas à Administração Pública, Gestão, Economia, Direito, Psicologia, Relações Internacionais e Políticas Públicas, enquanto que uma disciplina era específica às áreas de Antropologia e Sociologia.

Assim, nos atentamos sobre ementas de 20 disciplinas obrigatórias e eliminamos 18. Não consideramos na análise as disciplinas das áreas de Finanças Públicas, Orçamento, Contratos e Convênios, Estatística, Contabilidade e Sistemas de Informação, sendo 10 no total, uma vez que apresentariam poucas assimilações com o conteúdo pesquisado. Desconsideramos também as disciplinas referentes à estagio curricular obrigatório. Por fim, ao mesmo tempo, não consideramos as disciplinas optativas, as quais os alunos podem escolher como de livre formação, sendo três no total, assim como as de orientação de trabalho de conclusão de curso (duas no total).

Seguimos os processos de Baptista (2017), analisando ementas quanto: objetivo geral, objetivos específicos, ementa, conteúdo programático, referências bibliográficas. 
Neste sentido, procuramos observar se a ementa apresentaria alguma abordagem referente à gênero, racismo e homofobia em seus objetivos gerais, específicos e conteúdo programático. Paralelamente procuramos observar se a ementa possuiria alguma autora mulher nas referências bibliográficas. O objetivo, tendo em vista o sentido de Hooks (2013), é provocar o domínio de fato de autores homens brancos como totalizantes para a leitura da realidade social. Por fim, empreendemos uma terceira abordagem, para verificar se as ementas possuiriam algum autor negro nas referências bibliográficas. Guimarães (2013) destaca a dificuldade em atribuir uma cor/etnia à alguém, logo, procuramos às biografias dos autores que mencionassem sua raça e cor e, nos casos em que não existissem indicações, procedemos à eliminação do autor.

A IS510 - Estudos Antropológicos e Sociológicos na Administração Pública, aborda manifestações do mundo do trabalho, questões de gênero, sexualidade, etnias e religião. Já A disciplina IS526 - Administração Municipal, reconfigurou sua ementa, abrangendo refletir, analisar e discutir as políticas públicas, programas e projetos aplicados pelos municípios e refere estudos de casos acerca da saúde, educação, segurança transporte, meio ambiente, habitação, geração de renda, pobreza e miséria, políticas de combate às drogas, assistência social, gênero, sexualidade, populações em risco ou vulnerável. É a disciplina que claramente associa as dimensões de gênero, raça e sexualidade, não observado no PPC anterior.

IS506 - Fundamentos da Ciência Política no Campo de Públicas, aborda responsabilidade política do gestor público, democracia, representação e participação, a questão da cidadania e o papel do Administrador Público. IS509 - Teorias organizacionais destaca mudança e cultura, gestão social, ética tem bibliografia que aponta desigualdades e mudança social, sobretudo, estratégicas de desenvolvimento organizacional e suas relações.

Num primeiro momento podemos situar que quatro disciplinas de diferentes períodos apontam a incorporação desta dimensão do ethos democrático associado com perspectivas ampliadas de cidadania, observando a construção de melhores condições de vida e criação de ações de combate às desigualdades.

A disciplina IS507 - Fundamentos do pensamento administrativo, aponta administração pública gerencial e societal, cultura e Gestão. Tem como referência Alberto Guerreiro Ramos, esquecido em ementas de cursos de Administração Pública e um dos autores negros menos conhecidos no campo de públicas, pouco abordado em estudos sociológicos.

IS504 - Introdução à Administração Pública, trata de administração pública societal, ética, experiências inovadoras. IS503 - Comportamento Organizacional aborda cultura e aprendizagem organizacional.

Feitas estas considerações, podemos apontar alguns resultados referentes às 24 ementas analisadas:

a) IS508 - Sistema Político, Dinâmicas Econômicas e Instituições no Brasil aborda emergência de novos atores no processo político, movimentos sociais, organizações não governamentais. Aponta bibliografia extensa sobre movimentos e desigualdades socioeconômicas.

b) IS504 - Introdução à Administração Pública aborda administração pública societal, ética, experiências inovadoras 
c) IS503 - Comportamento Organizacional aborda cultura e aprendizagem organizacional

d) IS509 - Teorias Organizacionais destaca mudança e cultura, gestão social, ética. Tem bibliografia que aborda desigualdades e mudança social, sobretudo, estratégicas de desenvolvimento organizacional e suas relações.

e) IS512 - Políticas Públicas e Sociedade discute demandas do cidadão e as políticas, $O$ Estado frente às demandas dos cidadãos, conhecimento e problematização das políticas públicas pelos administradores públicos. É a disciplina que mais congrega autoras mulheres e discute temas de políticas e relações com a sociedade.

f) IS516 - Elaboração de Políticas Públicas (Integradora), aborda práticas de elaboração de políticas públicas, democracia, participação nos conselhos e conferências, políticas públicas para saúde, para a administração pública, ciência e tecnologia, educação, riscos e agricultura. A disciplina aborda questões acerca de mulheres e homossexuais na ementa, assim como apresenta bibliografia que aborda as ilusões de democracia nas políticas.

g) IS520 - Elaboração e Gestão de Projetos Públicos (Integradora) aponta a discussão de projetos públicos que promovam mudanças sociais.

h) IS522 - Sustentabilidade na Administração Pública aborda responsabilidade social, questão da cidade, a dicotomia urbano-rural e o ambiente equilibrado como desafio para a gestão pública. Situa aspectos ambientais e relação com a sociedade, assim como extensão universitária e responsabilidade social e indicadores de desenvolvimento sustentável.

i) IS523 - Avaliação de Políticas Públicas (Integradora), aborda estudos da avaliação de políticas públicas no Brasil, indicadores sociais, programas sociais, projetos sociais. apresenta literatura especializada acerca de planejamento de políticas públicas e avaliação com foco em políticas e projetos sociais.

j) IS524 - Gestão Estratégica de Pessoas na Administração Pública aborda o novo papel da área de recursos humanos e o papel do gestor público na gestão estratégica de pessoas. Apesar de não ser o foco vemos os estudos sobre o perfil e papel do gestor público em relação à administração pública, um foco distante da perspectiva privada na ementa anterior.

k) IS525 - Planejamento e Desenvolvimento Econômico Regional destaca novos processos locais de desenvolvimento, os aspectos econômicos sociais e culturais, dimensão humana do desenvolvimento. Aborda o papel das dimensões humanas e sociais e pode ter forte relação com desigualdades, apontando o papel estratégico da administração pública para a mudança social.

I) IS527 - Governança na Administração Pública, também foi reformulada, destacando agora governança pública e democracia, cidadania, participação social e governança interativa, governança global.

m) A ementa IH452 - Antropologia Social fazia menção explícita à questão de gênero e raça. Foi substituída pela IS510 - Estudos Antropológicos e Sociológicos na Administração Pública, que discute manifestações do mundo do trabalho, questões de gênero, sexualidade, etnias e religião e traz referências bibliográficas escritas por mulheres e autores negros. 
n) A ementa IH179 - Direito Constitucional I, que abrange elementos e promoção da cidadania e direitos, permanece no curso, apesar de não possuir autoras nem autores negros. No âmbito do Direito foi acrescida a $\mathrm{IH} 189$ - Direito Administrativo e Legislação, que possui autoras, apesar de não trabalhar com as temáticas. Foi retirada a disciplina TH552 - Introdução às Relações Internacionais, que pouco abordava a dimensão situada da desigualdade.

o) A disciplina IH668 - Projeto de Cidadania e Inclusão Social e IH452 Antropologia Social foram retiradas no novo PPCGAP/2017. Foram inclupidas IS510 - Estudos Antropológicos e Sociológicos na Administração Pública e a reformulada IS526 - Administração Municipal.

p) No ciclo de formação básica, 1ำ ao 4º período, do antigo PPCGAP/2010, das 14 disciplinas observadas apenas 5 faziam menção às temáticas relativas às desigualdades sociais, de classe, gênero, raça e sexualidade, ou seja, apenas

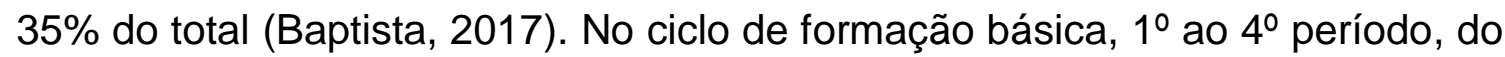
novo PPCGAP/2017, há nove disciplinas que fazem menção às temáticas relativas às desigualdades sociais, de classe, gênero, raça e sexualidade, ou seja, $64 \%$, tendo um salto qualitativo.

q) No PPCGAP/2010, das 24 ementas, 19 (79\%) continham referências bibliográficas compostas por autoras do sexo feminino. No PPCGAP/2017 são 21 ementas $(87,5 \%)$.

r) As ementas IS526 - Administração Municipal, IS512 - Políticas Públicas e Sociedade, IS516 - Elaboração de Políticas Públicas e IS527 - Governança na Administração Pública apresentam, respectivamente, 15, 9, 7 e 5 referências bibliográficas de autoras do sexo feminino. Sendo as duas primeiras compostas para o ciclo de formação básica e as duas seguintes para o ciclo de formação profissional.

s) As disciplinas IS526 - Administração Municipal, IS525 - Planejamento e Desenvolvimento Econômico Regional, IS522 - Sustentabilidade na administração pública, IS510 - Estudos Antropológicos e Sociológicos na Administração Pública e IS507 - Fundamentos do pensamento administrativo possuem autores negros em suas referências bibliográficas, notadamente, Milton Santos e Alberto Guerreiro Ramos.

$\mathrm{Na}$ tabela a seguir apresentamos a verificação de ementas, objetivos e bibliografia das disciplinas obrigatórias do curso de graduação em Administração Pública da UFRRJ. Em Baptista (2017) anotou-se os sobrenomes dos autores quando indicamos as referências bibliográficas. Todavia, não faria sentido repetir, já que se trata de atualização de ementas e criação de algumas novas. Assim, no âmbito da abordagem, apenas situamos se trabalham ou não com as temáticas indicadas, ao passo em que no âmbito de verificação de autoras e autores por gênero e raça/cor situamos o aspecto quantitativo, neste caso não eliminamos os autores - se um aparece em diferentes ementas, conta separadamente. 
Quadro 3 -

Verificação de ementas, objetivos e bibliografia das disciplinas obrigatórias do curso de graduação em Administração Pública da UFRRJ.

\begin{tabular}{|c|c|c|c|c|c|c|c|c|c|}
\hline \multicolumn{10}{|c|}{ 1ํPeríodo } \\
\hline \multicolumn{5}{|c|}{ Matriz 2010.2 } & \multicolumn{5}{|c|}{ Matriz 2017.2 } \\
\hline Cód. & Disciplina & $A B$ & MRB & AN & Cód. & Disciplina & $A B$ & MRB & AN \\
\hline IC251 & Matemática I & \multicolumn{3}{|c|}{ Não analisada } & IC251 & Matemática I & \multicolumn{3}{|c|}{ Não analisada } \\
\hline $\mathrm{IH} 297$ & $\begin{array}{l}\text { Fundamentos de } \\
\text { Macroeconomia }\end{array}$ & Não & 1 & Não & IS503 & $\begin{array}{l}\text { Comportamento } \\
\text { Organizacional }\end{array}$ & Sim & 2 & Não \\
\hline $\mathrm{IH} 129$ & $\begin{array}{l}\text { Introdução à } \\
\text { Administração }\end{array}$ & Não & 1 & Não & IS504 & $\begin{array}{l}\text { Introdução à } \\
\text { Administração } \\
\text { Pública }\end{array}$ & Sim & 1 & Não \\
\hline $\mathrm{IH} 147$ & $\begin{array}{l}\text { Psicologia Aplicada } \\
\text { à Administração }\end{array}$ & Não & 6 & Não & IS505 & $\begin{array}{l}\text { Metodologia de } \\
\text { pesquisa na adm. } \\
\text { pública }\end{array}$ & Não & 3 & Não \\
\hline $\mathrm{IH} 452$ & Antropologia Social & Sim & 1 & Não & IS506 & $\begin{array}{l}\text { Fundamentos da } \\
\text { Ciência Política no } \\
\text { Campo de Públicas }\end{array}$ & Sim & 2 & Não \\
\hline \multicolumn{10}{|c|}{ 2ำ Período } \\
\hline \multicolumn{5}{|c|}{ Matriz 2010.2 } & \multicolumn{5}{|c|}{ Matriz 2017.2 } \\
\hline Cód. & Disciplina & $\mathrm{AB}$ & MRB & AN & Cód. & Disciplina & $A B$ & MRB & AN \\
\hline $\mathrm{IH} 296$ & $\begin{array}{l}\text { Fundamentos de } \\
\text { Microeconomia }\end{array}$ & Não & Não & Não & $\mathrm{IH} 296$ & $\begin{array}{l}\text { Fundamentos de } \\
\text { Microeconomia }\end{array}$ & Não & Não & Não \\
\hline $\mathrm{IH} 122$ & $\begin{array}{l}\text { Contabilidade Geral } \\
\text { I }\end{array}$ & \multicolumn{3}{|c|}{ Não analisada } & $\mathrm{IH} 122$ & Contabilidade Geral I & \multicolumn{3}{|c|}{ Não analisada } \\
\hline $\mathrm{IH} 159$ & $\begin{array}{l}\text { Introdução à } \\
\text { Administração } \\
\text { Pública }\end{array}$ & Não & 1 & Não & $\mathrm{IH} 179$ & $\begin{array}{l}\text { Direito Constitucional } \\
\text { I }\end{array}$ & Sim & Não & Não \\
\hline $\mathrm{IH} 191$ & $\begin{array}{l}\text { Noções de Direito } \\
\text { Público e Privado }\end{array}$ & Não & 2 & Não & IS507 & $\begin{array}{l}\text { Fundamentos do } \\
\text { pensamento } \\
\text { administrativo }\end{array}$ & Sim & 1 & 1 \\
\hline IC280 & Estatística Básica & \multicolumn{3}{|c|}{ Não analisada } & IC280 & Estatística Básica & \multicolumn{3}{|c|}{ Não analisada } \\
\hline \multicolumn{10}{|c|}{ 3ำ Período } \\
\hline \multicolumn{5}{|c|}{ Matriz 2010.2} & \multicolumn{5}{|c|}{ Matriz 2017.2} \\
\hline Cód. & Disciplina & $\mathrm{AB}$ & MRB & AN & Cód. & Disciplina & $A B$ & MRB & AN \\
\hline $\mathrm{IH} 189$ & $\begin{array}{l}\text { Direito } \\
\text { Administrativo e } \\
\text { Legislação }\end{array}$ & Não & 1 & Não & $\mathrm{IH} 189$ & $\begin{array}{l}\text { Direito Administrativo } \\
\text { e Legislação }\end{array}$ & Não & 1 & Não \\
\hline $\mathrm{IH} 123$ & $\begin{array}{l}\text { Contabilidade Geral } \\
\text { II }\end{array}$ & \multicolumn{3}{|c|}{ Não analisada } & $\mathrm{IH} 297$ & $\begin{array}{l}\text { Fundamentos de } \\
\text { macroeconomia }\end{array}$ & Não & 1 & Não \\
\hline $\mathrm{IH} 130$ & $\begin{array}{l}\text { Matemática } \\
\text { Financeira }\end{array}$ & \multicolumn{3}{|c|}{ Não analisada } & IS508 & $\begin{array}{l}\text { Sistema Político, } \\
\text { Dinâmicas } \\
\text { Econômicas e } \\
\text { Instituições no Brasil }\end{array}$ & Sim & 10 & 1 \\
\hline $\mathrm{IH} 140$ & $\begin{array}{l}\text { Teoria e } \\
\text { Contabilidade de } \\
\text { Custos }\end{array}$ & \multicolumn{3}{|c|}{ Não analisada } & IS510 & $\begin{array}{l}\text { Estudos } \\
\text { Antropológicos e } \\
\text { Sociológicos na } \\
\text { Administração }\end{array}$ & Sim & 2 & 1 \\
\hline
\end{tabular}




\begin{tabular}{|c|c|c|c|c|c|c|c|c|c|}
\hline & & & & & & Pública & & & \\
\hline $\mathrm{IH} 431$ & $\begin{array}{l}\text { Sociologia Aplicada } \\
\text { à Administração }\end{array}$ & Sim & 3 & Não & IS509 & $\begin{array}{l}\text { Teorias } \\
\text { organizacionais }\end{array}$ & Sim & 2 & Não \\
\hline \multicolumn{10}{|c|}{ 4 Período } \\
\hline \multicolumn{5}{|c|}{ Matriz 2010.2 } & \multicolumn{5}{|c|}{ Matriz 2017.2 } \\
\hline Cód. & Disciplina & $A B$ & MRB & AN & Cód. & Disciplina & $A B$ & MRB & AN \\
\hline $\mathrm{IH} 179$ & $\begin{array}{l}\text { Direito } \\
\text { Constitucional I }\end{array}$ & Sim & Não & Não & IS511 & $\begin{array}{l}\text { Tecnologia da } \\
\text { informação I - } \\
\text { conceito, fundam. e } \\
\text { aplic. }\end{array}$ & \multicolumn{3}{|c|}{ Não analisada } \\
\hline $\mathrm{IH} 660$ & $\begin{array}{l}\text { Gestão Estratégica } \\
\text { de Pessoas na } \\
\text { Administração } \\
\text { Pública }\end{array}$ & Não & 2 & Não & $\mathrm{IH} 207$ & $\begin{array}{l}\text { Contabilidade } \\
\text { Nacional }\end{array}$ & \multicolumn{3}{|c|}{ Não analisada } \\
\hline $\mathrm{IH} 661$ & $\begin{array}{l}\text { Gestão de Projetos } \\
\text { Públicos }\end{array}$ & Não & 1 & Não & IS512 & $\begin{array}{l}\text { Políticas Públicas e } \\
\text { Sociedade }\end{array}$ & Sim & 9 & Não \\
\hline $\mathrm{IH} 662$ & $\begin{array}{l}\text { Políticas Públicas e } \\
\text { Sociedade }\end{array}$ & Sim & 9 & Não & IS513 & $\begin{array}{l}\text { Qualidade e } \\
\text { Produtividade no } \\
\text { Serviço Público }\end{array}$ & Não & Não & Não \\
\hline TH552 & $\begin{array}{l}\text { Introdução às } \\
\text { Relações } \\
\text { Internacionais }\end{array}$ & Sim & Não & Não & IS514 & $\begin{array}{l}\text { Gestão de Cadeia de } \\
\text { Suprimentos na } \\
\text { Administração } \\
\text { Pública }\end{array}$ & \multicolumn{3}{|c|}{ Não analisada } \\
\hline \multicolumn{10}{|c|}{ 5o Período } \\
\hline \multicolumn{5}{|c|}{ Matriz 2010.2 } & \multicolumn{5}{|c|}{ Matriz 2017.2 } \\
\hline Cód. & Disciplina & $A B$ & MRB & AN & Cód. & Disciplina & $A B$ & MRB & AN \\
\hline $\mathrm{IH} 207$ & $\begin{array}{l}\text { Contabilidade } \\
\text { Nacional }\end{array}$ & \multicolumn{3}{|c|}{ Não analisada } & IS515 & Orçamento Público & \multicolumn{3}{|c|}{ Não analisada } \\
\hline $\mathrm{IH} 663$ & $\begin{array}{l}\text { Qualidade e } \\
\text { Produtividade no } \\
\text { Serviço Público } \\
\text { (Foco na Gestão } \\
\text { Pública) }\end{array}$ & Não & 1 & Não & IS517 & $\begin{array}{l}\text { Gestão de Compras e } \\
\text { Licitação }\end{array}$ & \multicolumn{3}{|c|}{ Não analisada } \\
\hline $\mathrm{IH} 664$ & $\begin{array}{l}\text { Sistemas de } \\
\text { Informação I - } \\
\text { Conceitos, } \\
\text { Fundamentos e } \\
\text { Aplicação }\end{array}$ & \multicolumn{3}{|c|}{ Não analisada } & IS516 & $\begin{array}{l}\text { Elaboração de } \\
\text { Políticas Públicas } \\
\text { (Integradora) }\end{array}$ & Sim & 7 & Não \\
\hline $\mathrm{IH} 665$ & $\begin{array}{l}\text { Elaboração de } \\
\text { Políticas Públicas } \\
\text { (Integradora) }\end{array}$ & Sim & 9 & Não & IS518 & $\begin{array}{l}\text { Planejamento } \\
\text { Estratégico na } \\
\text { Administração } \\
\text { Pública }\end{array}$ & Não & 1 & Não \\
\hline- & Optativa & \multicolumn{3}{|c|}{ Não analisada } & IS519 & $\begin{array}{l}\text { Tecnologia da } \\
\text { Informação II }\end{array}$ & \multicolumn{3}{|c|}{ Não analisada } \\
\hline \multicolumn{10}{|c|}{ 60 Período } \\
\hline \multicolumn{5}{|c|}{ Matriz 2010.2 } & \multicolumn{5}{|c|}{ Matriz 2017.2} \\
\hline Cód. & Disciplina & $A B$ & MRB & AN & Cód. & Disciplina & $A B$ & MRB & AN \\
\hline $\mathrm{IH} 219$ & Finanças Públicas & & analis & & $\mathrm{IH} 219$ & Finanças Públicas & & analisa & \\
\hline
\end{tabular}




\begin{tabular}{|c|c|c|c|c|c|c|c|c|c|}
\hline IH666 & $\begin{array}{l}\text { Planejamento } \\
\text { Estratégico de } \\
\text { Estado }\end{array}$ & Sim & Não & Não & IS522 & $\begin{array}{l}\text { Sustentabilidade na } \\
\text { administração pública }\end{array}$ & Sim & 4 & 1 \\
\hline $\mathrm{IH} 668$ & $\begin{array}{l}\text { Disciplina } \\
\text { Integradora: Projeto } \\
\text { de Cidadania e } \\
\text { Inclusão Social } \\
\text { (Integradora) }\end{array}$ & Sim & 6 & Não & IS520 & $\begin{array}{l}\text { Elaboração e Gestão } \\
\text { de Projetos Públicos } \\
\text { (Integradora) }\end{array}$ & Sim & 3 & Não \\
\hline $\mathrm{IH} 667$ & $\begin{array}{l}\text { Responsabilidade } \\
\text { Sócio-Ambiental e } \\
\text { Sustentabilidade }\end{array}$ & Sim & 1 & Não & IS521 & $\begin{array}{l}\text { Gestão de Contratos, } \\
\text { Convênios e } \\
\text { Consórcios Públicos } \\
\text { (Integradora) }\end{array}$ & \multicolumn{3}{|c|}{ Não analisada } \\
\hline- & Optativa & \multicolumn{3}{|c|}{ Não analisada } & - & Optativa & \multicolumn{3}{|c|}{ Não analisada } \\
\hline \multicolumn{10}{|c|}{$7^{\circ}$ Período } \\
\hline \multicolumn{5}{|c|}{ Matriz 2010.2 } & \multicolumn{5}{|c|}{ Matriz 2017.2} \\
\hline Cód. & Disciplina & $\mathrm{AB}$ & MRB & AN & Cód. & Disciplina & $A B$ & MRB & AN \\
\hline $\mathrm{IH} 133$ & Orçamento Público & \multicolumn{3}{|c|}{ Não analisada } & IS524 & $\begin{array}{l}\text { Gestão Estratégica } \\
\text { de Pessoas na } \\
\text { Administração } \\
\text { Pública }\end{array}$ & $E / P$ & 4 & Não \\
\hline IH669 & $\begin{array}{l}\text { Planejamento e } \\
\text { Desenvolvimento } \\
\text { Econômico } \\
\text { Regional }\end{array}$ & Sim & 2 & 1 & IS525 & $\begin{array}{l}\text { Planejamento e } \\
\text { Desenvolvimento } \\
\text { Econômico Regional }\end{array}$ & Sim & 4 & 1 \\
\hline IH670 & $\begin{array}{l}\text { Gestão de Compras } \\
\text { e Licitação }\end{array}$ & \multicolumn{3}{|c|}{ Não analisada } & IS523 & $\begin{array}{l}\text { Avaliação de Políticas } \\
\text { Públicas (Integradora) }\end{array}$ & Sim & 4 & Não \\
\hline IH672 & $\begin{array}{l}\text { Gestão de } \\
\text { Contratos e } \\
\text { Convênios } \\
\text { (Integradora) }\end{array}$ & \multicolumn{3}{|c|}{ Não analisada } & $\begin{array}{c}\text { A } \\
\text { definir }\end{array}$ & $\begin{array}{l}\text { Trabalho de } \\
\text { Conclusão de Curso I }\end{array}$ & \multicolumn{3}{|c|}{ Não analisada } \\
\hline $\mathrm{IH} 671$ & $\begin{array}{l}\text { Projeto de } \\
\text { Pesquisa-Ação }\end{array}$ & Não & 2 & Não & - & Optativa & \multicolumn{3}{|c|}{ - } \\
\hline \multicolumn{10}{|c|}{ 8 Período } \\
\hline \multicolumn{5}{|c|}{ Matriz 2010.2 } & \multicolumn{5}{|c|}{ Matriz 2017.2 } \\
\hline Cód. & Disciplina & $A B$ & MRB & AN & Cód. & Disciplina & $A B$ & MRB & AN \\
\hline $\mathrm{IH} 106$ & $\begin{array}{l}\text { Administração } \\
\text { Municipal }\end{array}$ & Sim & 2 & Não & IS526 & $\begin{array}{l}\text { Administração } \\
\text { Municipal }\end{array}$ & Sim & 15 & 2 \\
\hline $\mathrm{IH} 673$ & $\begin{array}{l}\text { Negociação e } \\
\text { Arbitragem }\end{array}$ & Sim & Não & Não & IS528 & $\begin{array}{l}\text { Negociação, } \\
\text { Comunicação e } \\
\text { Arbitragem }\end{array}$ & $E / P$ & 1 & Não \\
\hline IH675 & $\begin{array}{l}\text { Governança na } \\
\text { Administração } \\
\text { Pública }\end{array}$ & Sim & 4 & Não & IS527 & $\begin{array}{l}\text { Governança na } \\
\text { Administração } \\
\text { Pública }\end{array}$ & Sim & 5 & Não \\
\hline IH674 & $\begin{array}{l}\text { Tutoria De Estágio } \\
\text { Curricular } \\
\text { Supervisionado }\end{array}$ & \multicolumn{3}{|c|}{ Não analisada } & AA451 & $\begin{array}{l}\text { Estágio Curricular } \\
\text { Supervisionado** }\end{array}$ & \multicolumn{3}{|c|}{ Não analisada } \\
\hline AA451 & $\begin{array}{l}\text { Estágio Curricular } \\
\text { Supervisionado }\end{array}$ & \multicolumn{3}{|c|}{ Não analisada } & $\begin{array}{c}\text { A } \\
\text { definir }\end{array}$ & $\begin{array}{l}\text { Trabalho de } \\
\text { Conclusão de Curso } \\
\text { II }\end{array}$ & \multicolumn{3}{|c|}{ Não analisada } \\
\hline
\end{tabular}






Fonte: elaborado pelo autor a partir de consulta ao site do curso ${ }^{3}$.

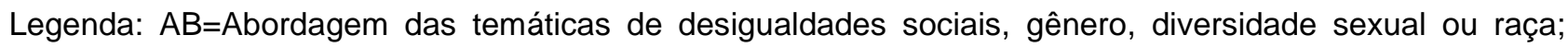
MRB=Mulheres das Referências Bibliográficas; $A N=$ =Autores e Autoras Negros.

\section{A construção de uma formação humanística do curso de graduação em Administração Pública da UFRRJ}

Em Baptista (2017) fizemos críticas à construção do projeto político pedagógico do curso em termos de finalidades, construções teóricas, bases normativas e perfil de egresso. Verificamos, de fato, um descompasso na formação humanística do curso, com pouca abordagem acerca das desigualdades, assim como a construção do perfil do próprio curso.

Contudo, devemos considerar que, assim como contextos sociais mudam, projetos curriculares também o fazem. Ao passo em que construções teóricas e cientificas também são passíveis de mudanças. Neste contexto, refaço minhas críticas acerca do desenvolvimento tomado pela reformulação do projeto pedagógico do curso de administração pública da UFRRJ.

Neste ponto, devemos considerar o sentido normativo dado pelas DCN no campo da Administração Pública, assim como o próprio fortalecimento do denominado campo de públicas. O sentido normativo que organiza o conceito e a prática no âmbito do interesse público e do egresso, cujo perfil seja comprometido com o desenvolvimento social e res publica somente veio apenas em 2014, logo, o PPCGAP/2010 não tinha como condensar perspectivas igualitárias ou garantidoras de direitos, quiçá ampliadas em combate às desigualdades, portanto, não é de se estranhar termos menções a sentidos gerencialistas, empreendedores parcialmente rasos ou situados em lógica do mercado.

As DCN de 2014 fizeram cumprir um impacto significativo no âmbito de delimitar que a Administração Pública é orientada por interesse público, epistemologias públicas e conceitos e metodologias pautadas por lógicas coletivas em que o Estado assume primazia da atuação observando contextos sociais que são objetivos na realidade pública. Assim, o PPCGAP/2017 incorpora estes elementos em seus princípios, objetivos e missão, assim como no perfil de egresso. O quarto princípio do curso - respeito às diferenças, diversidade e pluralidade de pensamento -, ao passo em que o objetivo do curso se modifica para o âmbito do desenvolvimento de ações voltadas para o interesse público, tendo em vista as complexidades e as contradições: este conceito e prática, a práxis, delineia um tipo de administração pública, com afeto ao público, ou seja, situar tanto interesse público quanto desenvolvimento.

O novo PPCGAP/2017 mantém referência a princípios de base conceitual de cidadania, ética, ethos democrático, democracia, desenvolvimento social os quais o referido projeto pedagógico faz menção recorrentemente. Já a missão tem mudança não apenas pela qualidade do texto em relação ao sentido de público empregado, mas por tentar demonstrar que o exercício da Administração Pública é voltada à sociedade e envolve grau de complexidade em aliar saber técnico à capacidade agregadora do ser e

${ }^{3}$ Disponível em <http://cursos.ufrrj.br/grad/admpublica/obrigatorias/Acesso em 30 jan. 2020.

Regae: Rev. Gest. Aval. Educ. Santa Maria $\quad$ v. 9 n. 18

p. $1-20$ 
agente público. Já no PPCGAP/2017 vemos um perfil de egresso que busca o incremento da cidadania e do desenvolvimento local e sustentável e se caracteriza pela visão ampla das necessidades da sociedade, que contribua para a melhoria da qualidade de vida dos indivíduos e cidadão; pela promoção do interesse público e pela expansão da participação da sociedade civil na gestão do Estado.

Consideramos como significativa a incorporação das definições de desigualdades, caráter do ethos republicano, da pluralidade e respeito às diferenças. Estes elementos não estavam presentes no PPCGAP/2010, o que deixava à margem de construções sociais em disputa sobre a finalidade da administração pública. Ter definindo, por exemplo, um conjunto de desigualdades e problemas públicos, torna o PPCGAP/2017 mais robusto à criação e transmissão de conhecimento socialmente impactante, tendo em vista atuar sobre elementos claros da realidade social e não em abstrações que, a depender do sentido conceitual atrelado à administração pública, pode-se considerar ou não como problemas.

O respeito e o combate às formas de discriminação trazem um elemento crítico ao projeto do curso, por não termos atrelado um sujeito parametrizado em lógicas distantes da realidade brasileira. Enquanto uma realidade de contrastes sociais, econômicos e políticos, não podemos deixar que projetos curriculares tenham sujeitos de justiça isentos de qualquer contextualização histórica de desigualdade ou afronta aos direitos. A Administração Pública é pública não pela indeterminação dos sujeitos; mas por abraçar a todos, indiscriminadamente.

Quanto às disciplinas é notória a incorporação das temáticas, passando de $35 \%$ para quase $65 \%$, tendo, obviamente, em consideração, que um curso como Administração Pública possui disciplinas que não necessariamente são do mesmo departamento e estão nas mãos dos professores vinculados, logo, não há domínio sobre algumas delas. Todavia, há salto expressivo na quantidade de disciplinas que passaram a abordar, inter e transdisciplinarmente, o contexto das desigualdades. Não obstante, tivemos acréscimo de autoras mulheres e autores negros que poderíamos situar como decolonização do pensamento se isso se situar nas práticas pedagógicas.

Vemos que as maiores mudanças estão no ciclo básico: $1^{\circ}$ ao $4^{\circ}$ período. Isso em duas interpretações: pelo sentido de delimitação do campo, da abordagem e princípio conceitual que organiza o curso: isso aponta para reestruturação do perfil do egresso, assim como da estabilidade das bases epistemológicas do próprio campo; impacto na retenção de aluno: o que situa que, quando se tem um curso bem definido em escopo, projeto e metodologia, a probabilidade de retenção de alunos ao longo do curso se aumenta. O ponto forte do novo PPCGAP/2017 é seu sentido de permear um conceito bem delimitado que incida sobre adesão aos princípios de Administração Pública voltada ao interesse público.

Portanto, quatro mudanças substanciais diferenciam os dois projetos pedagógicos no tempo e espaço: ampliação do escopo dos princípios pautados em ótica pública, com caráter democrático, respeitando o Estado de Direito e colocando a Administração Pública em lugar de destaque na resolução de problemas sociais e garantir dos direitos; 
delimitação direta e clara do objetivo do curso, situando crítica e reflexão para o interesse público; apontamento direto sobre missão de consciência crítica, competência técnica e engajamento sócio-político e ético para uma sociedade mais justa; olhar crítico para além das organizações, alcançando a sociedade e seu próprio papel enquanto gestor público.

\section{Considerações finais}

Neste texto discute-se os resultados da reformulação do projeto pedagógico do curso de graduação em Administração Pública de 2017 (PPCGAP/2017) da Universidade Federal Rural do Rio de Janeiro (UFRRJ) em cotejo com o PPCGAP de 2010 e as críticas contidas acerca deste em Baptista (2017).

Do total das 38 disciplinas que compõem a formação do discentes em créditos contidas no PPCGAP nos atentamos sobre ementas de 24 disciplinas obrigatórias. Analisamos as ementas quanto: objetivo geral, objetivos específicos, ementa, conteúdo programático, referências bibliográficas. No caso do novo PPCGAP/2017 da UFRRJ podemos apontar uma formação humanística. No ciclo de formação básica, do $1^{\circ}$ ao $4^{\circ}$ período, quase $65 \%$ das disciplinas abordam questões de desigualdade social, classe, gênero, raça e sexualidade. Devemos considerar que tivemos aumento das referências teóricas de mulheres, com $87,5 \%$ nas 24 ementas com autoras presentes. Algo a ser ressaltado é a presença de autores negros passando de uma para cinco ementas.

No novo PPCGAP/2017 há menção clara e direta aos tipos de desigualdades, violação de direitos e o compromisso do gestor público para com a resolução destes e outros problemas. Ressaltamos o fato do caráter do respeito, ethos republicano e perfil coadunado com perspectivas críticas e democráticas situadas no projeto pedagógico.

Ademais, situamos como positivo o PPCGAP/2017 não se pautar por lógicas de cidadão-cliente, notadamente usuais em uma administração pública que confunde dois conceitos que se são intransponíveis entre si: cliente, cuja lógica se pauta por relações de compra/venda, consumo/produção, cidadania.

Por fim, o que podemos apontar que o novo PPCGAP/2017 é pautado em sentido humanístico, crítico e situado em perspectiva democrática no âmbito de combate às desigualdades sociais. Podemos também destacar que foi resultado do impacto causado pelas DCN no âmbito da configuração do campo de públicas e fortalecimento de lógicas da administração pública distantes do sentido mercadológico.

\section{Referências}

BAPTISTA, Vinicius Ferreira. Diretrizes nacionais e o descompasso na formação humanística do curso de graduação em Administração Pública da UFRRJ. Regae Revista de Gestão e Avaliação Educacional, Santa Maria, v. 6, n. 13, 2017, p. 101-119.

BARROS, José D'Assunção. Igualdade e diferença: construções históricas e imaginárias em torno da desigualdade humana. Vozes: Petrópolis, 2016.

BENHABIB, Seyla. Dignity in adversity: human rights in troubled times. Cambridge: Polity, 2011.

BORILLO, Daniel. Homofobia: história e crítica de um preconceito. Belo Horizonte: Autêntica, 2015.

CARVALHO, José Murilo. Cidadania no Brasil: o longo caminho. Rio de Janeiro: Civilização Brasileira, 2013 
DAVIS, Angela. Mulheres, raça e classe. Boitempo: São Paulo, 2016

FRASER, Nancy. Scales of justice: reimagining political space in a globalizing world. New York, United States: Columbia University Press, 2009.

GUIMARÃES, Antonio Sergio Alfredo. Racismo e antirracismo no Brasil. São Paulo: 34, 2009

HONNETH, Axel. Suffering from indeterminacy: an attempt at the reactualization of hegel's philosophy of right - two lectures. Assen: Van Gorcum, 2000.

HOOKS, Bell. Ensinando e transgredir: a educação como prática da liberdade. São Paulo: Martins Fontes, 2013.

HOULSTON, James. Cidadania insurgente: disjunções da democracia e da modernidade no Brasil. Companhia das Letras: São Paulo, 2013.

MARSHALL, Thomas Humprey. Cidadania, classe social e status. Rio de Janeiro: Zahar Editores, 1967

MATIAS-PEREIRA. Curso de administração pública: foco nas instituições e ações governamentais. São Paulo: Atlas, 2010

PIRES, Valdemir Aparecido; MIDLEJ, Suylan de Almeida Midlej; FONSECA, Sérgio Azevedo; VENDRAMINI, Patrícia; COELHO, Fernando de Souza|. Campo de políticas públicas no Brasil: definição, movimento constitutivo e desafios atuais. Administração Pública e Gestão Social, Rio Claro, v. 6, n. 3, 2014, p. 110-126.

RAWLS, John. Justice as Fairness: $A$ restatement. Massachusetts: Harvard University Press, 2001.

UFRRJ. Projeto pedagógico do curso de Administração Pública de 2017. Seropédica: UFRRJ, 2017. Disponível em http://cursos.ufrrj.br/grad/admpublica/ppp-projeto-politicopedagogico. Acesso em 30 jan. 2020.

UFRRJ. Projeto pedagógico do curso de Administração Pública de 2010. Seropédica: UFRRJ, 2010.

YOUNG, Iris Marion. Responsability for Justice. Oxford: Oxford University Press, 2011.

Vinicius Ferreira Baptista é professor no Departamento de Administração Pública e no Programa de Pós-Graduação em Desenvolvimento Territorial e Políticas Públicas na Universidade Federal Rural do Rio de Janeiro.

https://orcid.org/0000-0002-8717-8332.

Endereço: UFRRJ - Departamento de Administração Pública, Rodovia BR-465 23897-000 - Seropédica - RJ - Brasil.

E-mail: viniciusferbap2007@hotmail.com.

Recebido em 30 de janeiro de 2020.

Aceito em 2 de maio de 2020.

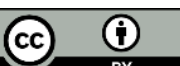

